\title{
In Vivo Assessment of Zinc Deficiency on Craniofacial Growth in a Rat Model
}

\author{
Cankat Kara \\ Recep Orbak ${ }^{a}$ \\ Ithan Metin Dagsuyu ${ }^{b}$ \\ Zerrin Orbak ${ }^{c}$ \\ Necmettin Bilicic \\ Kenan Gumustekin ${ }^{d}$
}

\section{ABSTRACT}

Objectives: The aim of this study was to investigate the effects of low levels of zinc intake on the rat mandible and maxilla during growth and to compare these results with those of zinc-containing rats.

Methods: The study was carried out on 14 Sprague-Dawley rats. The rats were randomly divided into two groups. Group I rats were fed with a Zn-deficient diet, and Group II rats with a Zn-containing diet. At the end of the fourth week on the experimental diet, all the rats were killed and blood samples were taken. Serum Zn levels were measured by atomic absorption spectrophotometry. Then, the skulls and mandibles were freed from soft tissues and measurements were made on the dry skulls, the mandibles, and teeth in both of the two groups.

Results: The zinc-deficient group showed a significantly lower value in dry skull, mandible, and teeth measurements when compared with those of the Group II.

Conclusions: Changes in zinc intake might exert an effect on the growth of craniofacial structures. A low-zinc diet during adolescence might slow bone and teeth growth and enhance the risk of oral, periodontal, and orthodontic problems in later years. (Eur J Dent 2009;3:10-15)

Key words: Zinc; Craniofacial growth; Rats.

Department of Periodontology, Ataturk University Faculty of Dentistry, Erzurum, Turkey.

b Department of Orthodontics, Ataturk University Faculty of Dentistry, Erzurum, Turkey.

c Department of Pediatric Endocrinology, Ataturk University Faculty of Medicine, Erzurum, Turkey.

d Department of Physiology, Ataturk University Faculty of Medicine, Erzurum, Turkey.

- Corresponding author: Dr. Cankat KARA Ataturk University Faculty of Dentistry Department of Periodontology 25240, Erzurum, Turkey

E-mail: mcankatahotmail.com

\section{INTRODUCTION}

Zinc is an essential trace element required for the growth of humans and other animals. ${ }^{1-3}$ Prasad et al ${ }^{1}$ described a syndrome characterized by dwarfism, hypogonadism, hepatosplenomegaly and zinc-deficiency. In later years, besides Iran, it has been reported from Egypt, Turkey, Portugal, Morocco, Yugoslavia, and other developing countries. $^{4-6}$ These reports represent awareness only in diagnosing overt cases, rather than the actual worldwide incidence of zinc deficiency. ${ }^{7}$ 
Zinc-deficiency in humans and animals causes a wide variety of symptoms, including impaired growth, alopecia, anemia, dwarfism, impaired sexual development, geophagia, dermatitis, loss of hair, poor appetite, abnormal dark adaptation, delayed wound healing and mental lethargy. ${ }^{1-7}$

To our knowledge, although a few of the general symptoms of zinc-deficiency have been reported in the studies published so far, ${ }^{1-9}$ its effects on the craniofacial structures have not been thoroughly described. ${ }^{10,11}$ In this study we attempted to investigate the effects of low levels of zinc intake on the dental, mandibular, maxillary and cranial dimensions of the rats, and to review the related literature.

\section{MATERIALS AND METHODS}

This investigation was carried out at the Physiology Animal Laboratory of Medical School (Ataturk University, Erzurum, Turkey). The study protocol was approved by the Ethics Committee of Ataturk University Faculty of Dentistry. In the study, 14 Sprague-Dawley rats with cessation of lactation on the $24^{\text {th }}$ day of birth were used. Rats were randomly divided into two groups: Group I rats were fed with a zinc-deficient diet, and Group II rats (controls) with a Zinc-containing diet (Table 1). ${ }^{12}$ The zinc-deficient diet was stored at $4.5 \pm 0.5^{\circ} \mathrm{C}$ in plastic containers and handled with plastic containers, plastic gloves, and appropriate utensils to avoid contamination. The diet was placed in shallow glass food cups with stainless steel follow-through disks to reduce food spills. The rats were kept individually in stainless steel cages and maintained at $22-25^{\circ} \mathrm{C}$ with a 12 -h light/ dark cycle. They were allowed free access to double-distilled water. Features of zinc deficiency, including cutaneous lesions, loss of appetite, slowed weight gain, loss of hair, diarrhea, and alopecia were observed in all zinc-deficient rats.

At the end of the fourth week on the experimental diet, all of the rats were killed by cardiac puncture after anesthesia with thiopental. Blood was removed directly from the heart. Blood samples were centrifuged at $3000 \mathrm{rpm}$ for five minutes and maintained at $-85^{\circ} \mathrm{C}$ until shortly before assay. Serum zinc level was measured by atomic absorption spectrophotometry (Flame type UNICAM 929).

The skulls and mandibles were freed from soft tissues and divided into two halves midsagittally (Figure 1). Then, the following 13 measurements were evaluated on the skulls, mandibles and teeth (Figure 2).

$L 1$ : Anterior edge of the glenoid fossa - extreme anterior extension of the maxillary bone between the incisors.

L2: Anterior edge of the glenoid fossa - junction of the mesial surface of the first molar with alveolar bone.

L3: Maximum skull length: the intersection of the frontoparietal suture and the interparietal suture on the midsagittal plane - most inferior point of the tympanic process.

L4: Posterior edge of the condyle - junction of the mesial surface of the first molar with alveolar bone.

L5: Posterior edge of the condyle - most anterior extension of the maxillary bone between the incisors.

L6: Posterior edge of the condyle - posterior rim of the mental foramen.

L7: Most superior surface of the condyle - line tangential to the inferior border of the mandible.

L8: Total skull length: most anterior point of the internasal suture in the midsagittal plane most posterior and external point of the squama occipitalis.

L9: Nasal length: most anterior point of the internasal suture in the midsagittal plane intersection of the nasofrontal suture and the internasal suture on the midsagittal plane.

L10: Interzygomatic width: the distance measured between the right and the left zygion points (most external point of the temporazygomatic suture on the zygomatic arcus).

L11: Maximum skull width: the distance measured between the right and the left squamosa temporalis points (most distant point of the squama temporalis from the midsagittal plane).

L12: Anterior teeth length of maxilla: the distance between the incisive edges of anterior tooth and the margin of gingiva.

L13: Anterior teeth length of mandible: the distance between the incisive edges of anterior tooth and the margin of gingiva.

Statistical analysis

Statistical analysis was performed using SPSS 11.0 for Windows. The statistical significance 
of data for all scores between the groups was determined with the Student t-test. Changes were considered significant at the $\mathrm{P}<.05$ levels.

\section{RESULTS}

Group I (fed with zinc-deficient diet) consisted of seven rats (five females, two males); Group II (fed with zinc-containing diet) contained seven rats (four females, three males). The rats were fed similar nutrition except zinc. The first observation was growth retardation, poor appetite, loss of hair, diarrhea, and ulcerations of the skin and mucosa in the zinc-deficient rats. These findings were

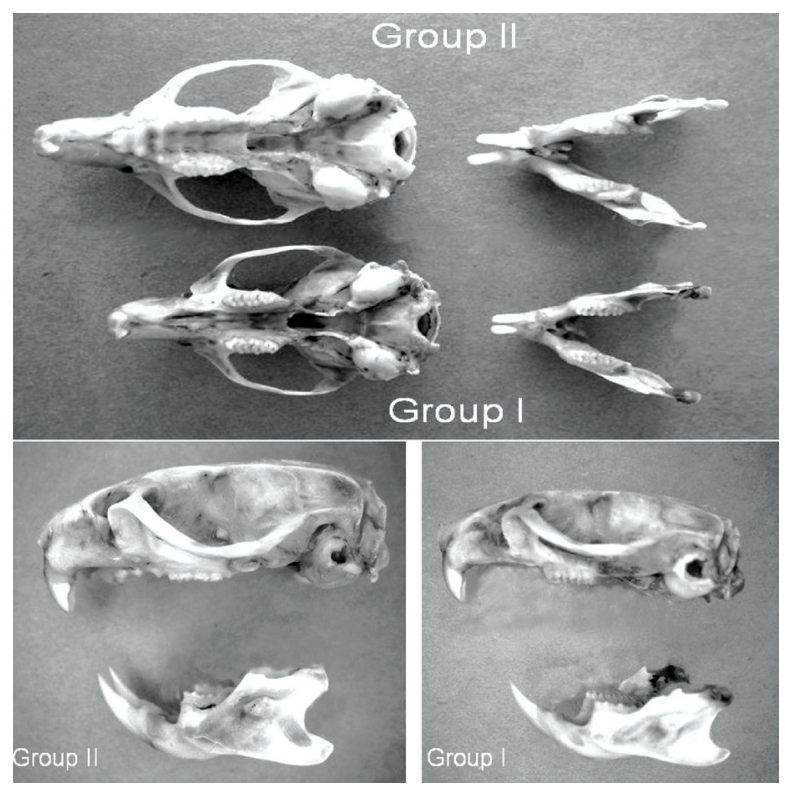

Figure 1. The skulls and mandibles in the transversal and sagittal plane.

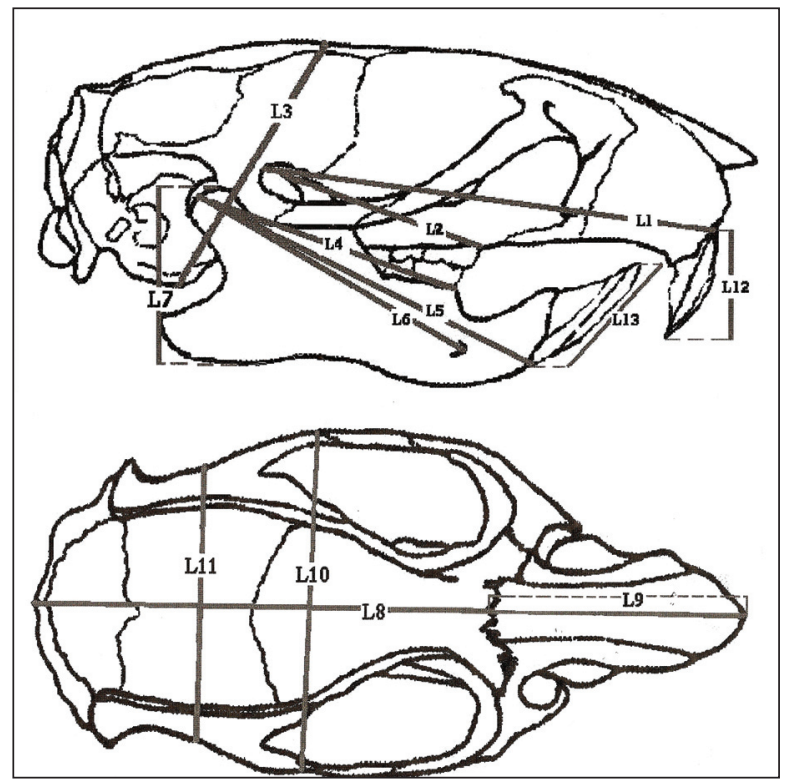

Figure 2. Cranial and mandibular measurements in the transversal and sagittal plane. observed at the 10-16 days in zinc-deficient rats. Although body weight, body length and tail length were retarded in zinc-deficient rats, they were advanced in rats fed with a zinc-containing diet (Figure 3). Serum zinc level of the zinc-deficient rats (Group I) was lower than that of the controls (Group II) (P<.001) (Table 2).

A statistically significant difference was found in the entire total craniofacial parameters measured between the groups. It was determined that maxillary and mandible lengths were smaller in the zinc-deficient rats than those of the zinccontaining diet rats. The incisor and molar teeth were more anteriorly located on Group II as compared to Group I at 30 days age (L1, L2). The length of the mandible as measured from the condyle to the molars (L4), incisors (L5) or to the mental foramen (L6) was anteriorly located on the Group II as compared to Group I. The height of ramus (L7) was increased on Group II at 30 days age. Longitudinal measurements, such as total skull length (L8), nasal length (L9), interzygomatic width (L10) and maximum skull width (L11), were also significantly shorter at zinc-deficient rats. The length of root and clinical crown of teeth were longer in Group II as compared to Group I (L12, L13) (Table 3). The zinc-deficient group showed a significantly lower value in dry skull, mandible, and teeth measurements when compared with those of Group II (P<.001) (Table 3).

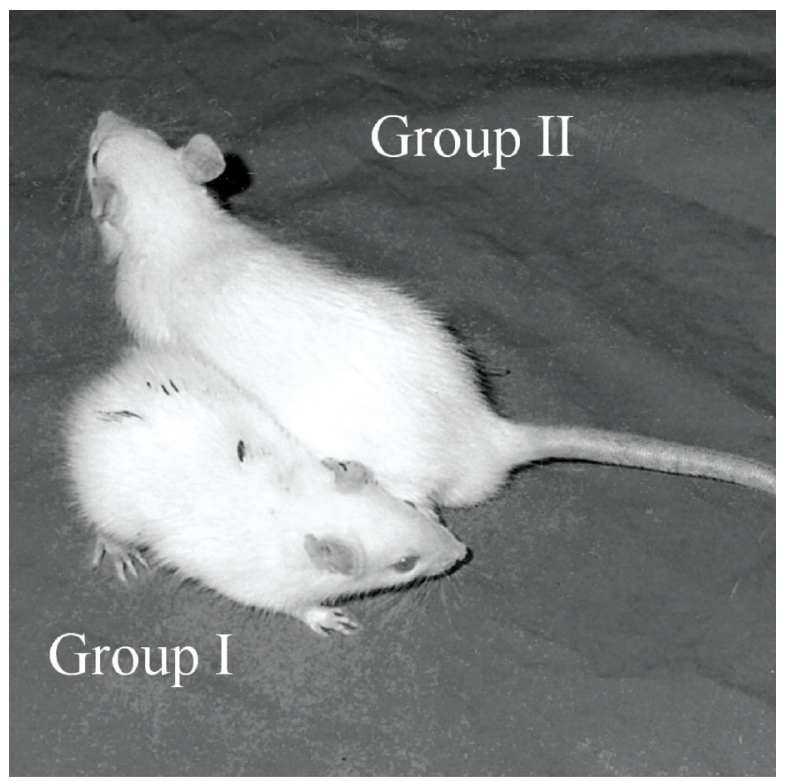

Figure 3. Group I rats were given a zinc-deficient diet. Group II rats (controls) were given a zinc-containing diet. 


\section{DISCUSSION}

In the study the effects of zinc-deficiency on the skull, mandible, and teeth during growth were evaluated in rats. Zinc has been demonstrated to be essential for normal growth of the human skeleton and also for skeletal growth in many animals. ${ }^{13}$ It is known that rats are more susceptible than other animals to zinc-deficiency. It therefore provides a useful model for the study of the effects on the rat craniofacial structures of dietary zinc-deficiency during growth. Zinc is the second most abundant trace metal in the human body and is present in all living cells and body secretions. ${ }^{2}$ In addition, the most recent research reported that zinc-deficiency could have marked effects on virtually all components of the immune system. ${ }^{14}$ Our observations of growth retardation in zinc-deficient rats and growth acceleration in zinc-added rats have confirmed that zinc is an important element for growth. Orbak et $\mathrm{al}^{3}$ in their study, which was aimed at evaluating the alterations of oral and periodontal tissues in zincdeficient rats, also found that oral health was better in rats (those fed with zinc containing diet) than in rats (zinc-deficient) and showed that zincdeficiency was a potential risk factor for oral and periodontal diseases.

Although clinical features are important, zinc-deficiency must be confirmed by laboratory findings. Zinc status was evaluated in many studies by direct analysis of zinc concentrations in serum spectrophotometry. ${ }^{15,16}$ We also used this method.

The effects of zinc-deficiency are similar in most animal species and include dermatitis, alopecia, ocular lesions, testicular atrophy, growth retardation and anorexia. Zinc is the most abundant trace element in bone, being present at a concentration of up to $300 \mu \mathrm{g} / \mathrm{g}$, and it has been considered an important factor in bone metabolism. Skeletal changes, including delayed maturation, reduced alkaline phosphates activity, reduced premenopausal bone mass and postmenopausal osteoporosis, have been associated with zincdeficiency. ${ }^{17}$

Zinc-deficiency is associated with skeletal growth retardation and reduction in bone mass. The morphometric abnormalities of the growth plates, likely linked to the role of zinc in cell division, differentiation, and apoptosis, explain the skeletal longitudinal growth retardation and the greater deformability of the long bones in zincdeficient rats than in the control rats. ${ }^{17}$ In this study we especially investigated the effects of low

Table 1. Composition of $\mathrm{Zn}$-deficient diet and $\mathrm{Zn}$-containing diet12.

\begin{tabular}{lccc}
\hline Ingredient & \multicolumn{2}{c}{ DIET(kg) } & Group II \\
\hline Egg white & $\%$ & Group I & 0.700 \\
DL-Methionine & 70 & 0.700 & 0.010 \\
Sucrose & 1 & 0.010 & 0.123 \\
Corn oil & 12.3 & 0.123 & 0.100 \\
Cellulose & 10 & 0.100 & 0.020 \\
Choline Bitartrate & 2 & 0.020 & 0.002 \\
AIN-76 Mineral Mix ${ }^{\text {a }}$ & 0.2 & 0.002 & 0.035 \\
AlN-76 Vitamine Mix & 3.5 & $0.035(Z n$ deficient) & 0.010 \\
Total & 1 & 0.010 & $1 \mathrm{~kg}$ \\
\hline
\end{tabular}

a Mineral Mixture: Calcium Phosphate 17.500g, Sodium Chloride 2.590g, Potassium Citrate Monohydrate 7.700g, Potassium Sulfate 1.820g, Magnesium Oxide 0.840g, Potassium lodate 0.350mg, Manganous Carbonate 0.123g, Chromium Potassium Sulfate $19.250 \mathrm{mg}$, Sodium Selenite $0.350 \mathrm{mg}$, Ferric Citrate $0.210 \mathrm{~g}$, Cupric Carbonate $10.500 \mathrm{mg}$, Zinc Carbonate $0.056 \mathrm{~g}$ (for only group II), Sucrose $4.187 \mathrm{~g}$ for group I (finely powdered $35.000 \mathrm{~g}$ ) and Sucrose $4.130 \mathrm{~g}$ for group II (finely powdered $35.000 \mathrm{~g}$ ).

b Vitamin Mixture : Thiamine Hydrochloride 0.600g, Riboflavin 0.600g, Pyridoxine Hydrochloride 0.700g, Nicotinic Acid 3.000g, D-Calcium Pantothenate 1.600g, Cyanocobalamin 1.000mg, Vitamin A 0.800g, DL-alpha-Tocopherol Acetate 0.400g, Cholecalciferol $1.000 \mathrm{mg}$, Menaquinone $3.000 \mathrm{mg}$, Folic Acid 0.200g, D-Biotin 0.02g, Sucrose 2.079g (finely powdered $10.000 \mathrm{~g}$ ). 
levels of zinc intake on rat teeth, mandible, and maxilla during growth.

In the present study, all lengths' means of the rats in the zinc-deficient group were significantly shorter than the means in the control group $(P<.001)$. The low growth of the maxilla was seen besides the results of measuring the lengths in the zinc-deficient group as compared to the control group. And also glenoid fossa was more anteriorly located on the zinc-deficient group rats' skulls. The lengths of the mandible as measured from the condyle to the molars (L4), incisors (L5) or to the mental foramen (L6) were decreased in the rats, which were fed with a zinc-free diet. The height of the ramus (L7) was also decreased in the zinc-deficient group. Both maxilla and mandible's growing quantity was greater in the rats that were fed with the zinc-rich diet. The differences in the length and height measurements between the zinc deficient and control group were seen in the Table 3.

Although there were no differences between two groups about the lengths of teeth $(P>.05)$, the decrease of the teeth lengths in the zinc-deficient group was seen in Table 3. In those rats fed with a zinc-containing diet, L12, L13 were increased. But, the differences in L12, L13 values for Group I and Group II were not found to be statistically significant ( $P>$.05).

The role of zinc in bone metabolism was shown by its stimulatory effect on bone formation in tissue culture, ${ }^{18}$ bone growth, and mineralization in weaning rats, ${ }^{19}$ and potent inhibitory effect in vitro on bone resorption. ${ }^{20}$ There are few known reports demonstrating what effect changes in zinc intake might exert on osseous tissue during the growth stage. Gloub et $\mathrm{al}^{21}$ reported that a lowzinc diet during adolescence might slow bone growth, enhancing the risk of osteoporosis in later years. Weisman and Hoyer ${ }^{22}$ reported that zincdeficiency reduced the sensitivity of receptors to growth hormone. Elberle et $\mathrm{al}^{23}$ compared the counts of various cells active in bone formation in

Table 2. Comparison of serum zinc levels $(\mu \mathrm{g} / \mathrm{dL})$ of the groups.

\begin{tabular}{llll}
\hline Groups & $\mathrm{n}$ & Mean \pm SD & $\mathrm{P}$ \\
\hline Group I & 7 & $0.84 \pm 0.26$ & $*$ \\
Group II & 7 & $3.80 \pm 0.28$ & $*$ \\
\hline
\end{tabular}

rats fed normal diet with those in rats fed a zincdeficient diet and reported that the osteoblast count was reduced more significantly in the zincdeficient group than in the normal diet group. Kenshi et $\mathrm{al}^{24}$ found the changes in zinc intake might exert an effect on the osseous tissue of the mandible and femur. The zinc-deficient group showed significantly lower trabecular and cortical bone density compared with the control group in the mandible. And also, in an animal study, it was found that the zinc-deficient diet caused a decrease in body weight and long bone lweight and length) growth. Growth impairment was significantly greater in zinc deficient rats than in control rats. ${ }^{17}$ Ovesen et $\mathrm{al}^{13}$ showed that zincdeficiency in growing rats induced a reduction of bone strength in the femoral neck, the distal femoral metaphysis, and the femoral diaphysis. The bone abnormalities in zinc-deficient rats are caused not only by changes in the growth plate cartilage, but also by changes in the bone size.

\section{CONCLUSIONS}

The zinc-deficient group showed a significantly lower value in dry skull, mandible and teeth

Table 3. Measurements (distances, $\mathrm{L}$, in $\mathrm{mm}$ ) made on the teeth, skulls, and mandibular halves of 14 rats.

\begin{tabular}{l|c|c|c}
\hline Variable & Group I & Group II & P \\
\hline L1 & $19.0 \pm 0.43$ & $25.3 \pm 1.26$ & $*$ \\
\hline L2 & $9.3 \pm 0.50$ & $12.5 \pm 0.73$ & $*$ \\
\hline L3 & $11.7 \pm 0.45$ & $14.2 \pm 0.56$ & $*$ \\
\hline L4 & $12.8 \pm 0.46$ & $16.2 \pm 0.51$ & $*$ \\
\hline L5 & $19.0 \pm 0.52$ & $23.8 \pm 0.93$ & $*$ \\
\hline L6 & $13.9 \pm 0.49$ & $17.3 \pm 0.66$ & $*$ \\
\hline L7 & $7.3 \pm 0.36$ & $9.7 \pm 0.53$ & $*$ \\
\hline L8 & $27.9 \pm 0.21$ & $35.4 \pm 0.43$ & $*$ \\
\hline L9 & $10.1 \pm 0.41$ & $13.4 \pm 0.29$ & $*$ \\
\hline L10 & $14.2 \pm 0.16$ & $18.9 \pm 0.18$ & $*$ \\
\hline L11 & $10.7 \pm 0.30$ & $13.2 \pm 0.15$ & $*$ \\
\hline L12 & $4.4 \pm 0.15$ & $5.1 \pm 0.10$ & NS \\
\hline L13 & $8.5 \pm 0.29$ & $9.2 \pm 0.22$ & NS \\
\hline
\end{tabular}

Results are expressed as Mean \pm SD

*: $\mathrm{P}<.05$ significant differences between the groups NS: not statistically significant 
measurements when compared with those of the zinc-containing group. Zinc plays an important role in bone growth and stimulates bone formation and mineralization. Changes in zinc intake might exert an effect on the osseous tissues of the jawbones and teeth during the growth stage. A low-zinc diet during adolescence might slow bone and teeth growth and enhance the risk of oral in later years.

\section{REFERENCES}

1. Prasad AS, Miale A, Farid Z. Zinc metabolism in patients with the syndrome of iron deficiency anemia, hepatosplenomegaly, dwarfism and hypogonadism. $J$ Lab Clin Med 1963;61:537-547.

2. Kara C, Beldüz N, Kara I, Demir T. Zinc: Basic functions and importance on human health. Sendrom 2007;19:51-58.

3. Orbak R, Kara C, Özbek E, Tezel A, Demir T. Effects of zincdeficiency on oral tissues and periodontal diseases in rats. J Periodontal Res 2007;42:138-143.

4. Endre L, Beck FWJ, Prasad AS. The role of $\mathrm{Zn}$ in human health. J Trace Elem Exp Med 1990;3:337-375.

5. Bodgen JD. Blood zinc in health and disease. In Epidemiological aspects of human zinc deficiency. Eds Casey CE, Hambidge KM. 1980;1-27.

6. Cavdar AO, Arcasoy A, Cin S, Gumus H. Zinc deficiency in geophagia in Turkish children and response to treatment with zinc sulphate. Haematol 1980;65:403-408.

7. Prasad AS. Clinical manifestations of zinc deficiency. Annu Rev Nutr 1985;5:341-363.

8. MacDonald RS. The role of zinc in growth and cell proliferation. J Nutr 2000;130:1500-1508.

9. Prasad AS. Recognition of zinc-deficiency syndrome. Nutrition 2000;17:67-69.

10. Maragou P, Ivanyi L. Serum zinc levels in patients with burning mouth syndrome. Oral Surg Oral Med Oral Pathol 1991;71:447-450.

11. Teraki Y, Ishiyama M. Studies on the distribution of mineral elements in the tooth of zinc-deficient rats. Shigaku 1990;78:251-257.

12. Bieri JG. AIN-76 diet. J Nutr 1979;109:925-926.

13. Ovesen J, Moller-Madsen B, Thomsen JS, Danscher G, Mosekilde LI. The positive effects of zinc on skeletal strength in growing rats. Bone 2001;29:565-570.

14. Prasad AS. Zinc and growth. J Am Coll Nutr 1996;15:341342.

15. Bates J, McClain CJ. The effect of severe zinc deficiency on serum levels of albumin, transferrin, and prealbumin man. Am J Clin Nutr 1981;34:1655-1660.
16. Endre L. Recurrent aphthous ulceration with zinc deficiency and cellular immune deficiency. Oral Surg Oral Med Oral Pathol 1991;72:559-561.

17. Laura R, Silvia M, Alessandro C, Marilena M, Paolo B, Anna $T$, et al. Reduced growth and skeletal changes in zinc deficient growing rats are due to impaired growth plate activity and inanition. $J$ Nutr 2001;131:1142-1146.

18. Hurley LS, Gowan J, Milhaud G. Calcium metabolism in manganese deficient and zinc deficient rats. Proc Soc Exp Biol Med 1969;130:856-860.

19. Becker WM, Hoekstra WG. Effect of vitamin D on Zn-65 absorption and turnover in rats. J Nutr 1966;90:301-309.

20. Holloway WR, Collier FM, Herbst RE, Hodge JM, Nicholson GC. Osteoblast-mediated effects of zinc on isolated rat osteoclasts: inhibition of bone resorption and enhancement of osteoclast number. Bone 1996;19:137-142.

21. Gloub MS, Keen, CL, Gershwin ME, Styne DM, Takeuchi PT, Ontell $F$, et al. Adolescent growth and maturation in zinc deprived rhesus monkeys. Am J Clin Nutr 1996;64:274-282.

22. Weismann K, Hoyer H. Serum alkaline phosphates and serum zinc levels in the diagnosis and exclusion of zinc deficiency in man. Am J Clin Nutr 1985;41:1214-1219.

23. Eberle J, Schmidmayer S, Erben RG, Stangassinger M, Roth HP. Skeletal effects of zinc deficiency in growing rats. J Trace Elem Exp Med 1999;13:21-26.

24. Kenshi M, Takahiro N, Ikuko N, Shigeru U, Mitsutaka K. Effect of zinc on rat mandibles during growth. Am J Orthod Dentofacial Orthop 2002;122:410-413. 